${ }^{1}$ Ninewells Hospital, Dundee, UK ${ }^{2}$ Scottish Centre for Simulation and Clinical Human Factors, Larbert, UK

${ }^{3}$ National Lead for Clinical Skills and Simulation, Clinical Skills Managed Education Network, NHS Education for Scotland, Dundee, UK

${ }^{4}$ College of Medicine, Dentistry and Nursing, Academic Business Development Hub, University of Dundee, Dundee, UK

\section{Correspondence to} Dr Jean Ker, College of Medicine, Dentistry and Nursing, Academic Business Development Hub, University of Dundee, Leve 10, Ninewells Hospital and Medical School, Dundee DD1 9SY, UK; j.s.ker@dundee.ac.uk

Received 9 June 2015 Revised 9 September 2015 Accepted 13 October 2015 Published Online First 27 November 2015

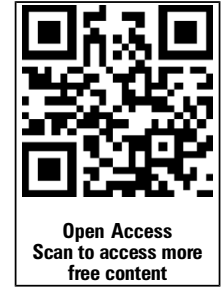

CrossMark

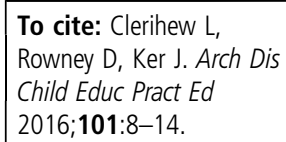

To cite: Clerihew $\mathrm{L}$,

Rowney D, Ker J. Arch Dis

Child Educ Pract Ed

2016;101:8-14.

\title{
Simulation in paediatric training
}

\author{
Linda Clerihew, ${ }^{1}$ David Rowney, ${ }^{2}$ Jean $\mathrm{Ker}^{3,4}$
}

We are what we repeatedly do. Excellence then is not an act but a habit

Aristotle

\section{INTRODUCTION}

This quote from the Greek philosopher Aristotle from over 2000 years ago is still relevant today in the context of paediatric medical education. Simulation is a tool that can reinforce standards of clinical practice as 'habit' contributing to trainee's development as paediatricians.

This review shares some of the issues related to learning in the paediatric service environment and demonstrates how simulation can add benefit and value to both the educational process and clinical service. We have structured the article around a series of questions, which will be of relevance to all those using simulation for paediatric training.

\section{WHAT IS SIMULATION?}

It is important to have a shared mental model of what we mean by simulation, David Gaba ${ }^{1}$ describes it as 'a technique, not a technology to replace or amplify real experiences with guided experiences that evoke or replicate substantial aspects of the real world in a fully interactive manner'.

It provides a safe context where confidence as well as competence can be continuously enhanced with excellence as the goal for patient care. ${ }^{23}$

The term simulation can be used to describe simulated patients; either manikin or actors, or simulated scenarios in either a simulated environment, for example, simulation centre, or simulated situation in the clinical environment known as in situ simulation.

The recognition of the importance of simulation in clinical education originated from its impact in other high-reliability organisations, such as aviation, the military and the oil industry. ${ }^{4}$ Our increased understanding of systems thinking and ensuring the provision of consistent high quality care in different healthcare settings has highlighted how simulation can be used for many purposes ${ }^{5}$ including enhancing the design of new delivery systems.

\section{WHY ARE WE USING SIMULATION FOR PAEDIATRIC TRAINING?}

There are several drivers for using simulation in paediatric training. First are the hours available for training. An increased knowledge of the impact of stress and fatigue on safe decision making and clinical performance ${ }^{6}$ has led to a decrease in trainee's service hours with the knock on impact of limiting their clinical experience. Complex rota systems are also reducing the continuity of training and opportunities to ensure issues, identified from workplace-based assessments, are followed up. Second, paediatric services are now target-driven in terms of throughput and cost, and this can impact on available time for training, ${ }^{7}$ particularly on ward rounds and in clinics. Although the clinical environment in paediatrics offers the chance to learn about a large volume of common presentations, ${ }^{8} 9$ clinical signs rapidly resolve, and patient turnover in paediatrics is often faster than in adult-based specialities, and time to develop clinical expertise is limited. It can be challenging for trainees, at whatever level of expertise, to gain consent from parents to examine their often distressed, sick child. ${ }^{10}$ In the service environment, the patient is the priority (box 1).

Many countries are also experiencing increased demands on paediatric clinical services, which are increasingly encompassing a wider remit in terms of the social responsibilities of child health and well-being. ${ }^{11}$

\section{WHAT CAN SIMULATION BE USED FOR IN PAEDIATRIC TRAINING?}

Simulation in paediatric training can be used to enhance learning from practice. It provides an educational bridge to prepare trainees for the reality of practice ${ }^{12}$ while protecting patients. One of the most 


\section{Box 1 Challenges for safe effective learning}

Lack of staff to cross cover training opportunities

Reduced training hours

Patients intimidated by large groups

Young patients difficult to examine

Rapid resolution of clinical signs

Few very sick patients

Trainee concerns re-making mistakes in front of patients

understated uses of simulation is the opportunity to develop generic skill competences such as selfawareness and critical thinking. ${ }^{13}$

In paediatrics, simulation has been used to develop technical skills such as procedural skills ${ }^{14-17}$ and nontechnical skills such as team-working, communication, leadership, decision-making and situational awareness. ${ }^{18-20}$ Human factors training is exemplified by the Imperial Paediatric Emergency Training Toolkit which provides a psychometric tool for training in emergencies. ${ }^{21}$ There is also SPRinT (Simulated Paediatric Resuscitation Team Training) for health professionals run at the Royal Brompton and Royal Marsden. $^{22}$

Common technical and non-technical skills that can be developed using simulation are highlighted in table 1 .

Common scenarios that can be developed using simulation are in box 2 adapted from Ahmed et al. ${ }^{2}$

\section{WHAT IS THE EVIDENCE THAT SIMULATION WORKS?}

Most of the reported evidence to date has been related to emergency situations. ${ }^{23}$ An enormous benefit of simulation is that skills can be built, elaborated on reinforced and refined in line with the latest evidence and can be learnt at relevant times using a systematic and structured approach in a curriculum. ${ }^{5}$ It also provides an opportunity for trainees to learn from other reported common adverse events such as medication errors, communication failures and failure to recognise and escalate care of deteriorating patients.

There has also been encouraging evidence of patient benefits in terms of reduced admissions and length of

Table 1 Technical and non-technical skills

\begin{tabular}{ll}
\hline Technical skills & Non-technical skills \\
\hline History taking & Communication and teamwork \\
Physical examination & Leadership \\
Communication skills & Professionalism \\
Procedural skills & Situational awareness \\
Manual handling & Prioritisation skills \\
Documentation skills & Decision-making \\
\hline
\end{tabular}

\section{Box 2 Scenarios for simulation}

Undertaking an invasive procedure such as a cannulation or lumbar puncture on an unwell toddler

- Leading a resuscitation or practising a diseasespecific pathway, for example, sepsis

- Leading a clinical assessment of potential child sexual abuse

- Writing paediatric medicines and fluid prescriptions

- Performing the appropriate referrals and investigations after a SUDI

- Communication with child and family in relation to breaking bad news or discussing a CYPADM decision.

- Leading a debriefing with an interprofessional team following a failed resuscitation

- Managing a colleague with performance issues

- Explaining a medication error to child and family CYPADM, Children and Young Persons Acute Deterioration Management Plan; SUDI, sudden unexpected death in infancy.

stay through the use of simulation. ${ }^{24}$ This reflects other specialities experience in obstetrics Draycott et al have reported improved APGAR scores and better patient outcomes in perinatal shoulder dystocia. ${ }^{25}$ Decreased central venous catheter associated line infection and insertion complications ${ }^{26}$ and better patient outcomes following angioplasty have resulted from simulation-based training. ${ }^{27}$

There is a growing body of evidence in paediatrics in relation to the use of in situ simulation training. These include improved cardiopulmonary arrest survival rates after the introduction of simulated mock codes, ${ }^{28}$ earlier recognition of sick patients with more rapid escalation to the paediatric intensive care unit and decreased mortality ${ }^{24}$ after the introduction of in situ team training for paediatric emergencies, and decreased serious safety events in an emergency department. $^{29}$

The international trend towards providing a seamless integrated competency-based paediatric programme from undergraduate through postgraduate to continuing professional development in clinical training $^{9}{ }^{30}$ provides a framework for simulation to be used to its maximum potential.

\section{WHAT ARE THE BENEFITS OF SIMULATION IN PAEDIATRIC TRAINING?}

The following summarises the current benefits of simulation for teaching and learning in the paediatric environment reported from the international literature. Between $10 \%$ and $30 \%$ of paediatric inpatients are harmed by the care they receive. ${ }^{31}$ In "Why Children Die', the confidential enquiry report into 
Maternal and Child Health in the UK, 26\% of child deaths were identified as avoidable. ${ }^{32}$ These provide powerful learning lessons for trainees, particularly in relation to the variation in the system and the latent safety threats. ${ }^{4}$ Latent safety threats are potential hazards, which lie unrecognised and dormant, often for a significant period of time, before contributing to a significant safety event. One of the benefits of simulation is providing trainees with a framework to analyse such incidents, identify active and latent failures to redesign the system and test out options in a simulated environment to avoid any further unintended harm.

For junior trainees, simulation can be used to gain confidence in taking histories or examining young patients and for more experienced trainees, can provide a breadth of exposure to rarer presentations, for example, paediatric resuscitations, breaking bad news and safeguarding. Simulation enables a critical event to be deconstructed into learnable chunks so that generic competences such as leadership, prioritisation and communication can be explored and refined. These opportunities can be used as part of an integrated educational package using 'digital toolbox' with instant messaging and $24 \mathrm{~h}$ access to education and learning in terms of, for example, webexes, podcasts and vod-casts. Simulation is increasingly used as part of a blended learning approach to enhance skills retention and prevent skill decay. ${ }^{33}$

\section{WHAT ARE THE CHALLENGES OF USING SIMULATION IN PAEDIATRIC TRAINING?}

Despite a growing enthusiasm for simulation, there continues to be barriers to its widespread adoption. The most commonly cited reasons are resource constraints due to time, finance or an inability to access simulation centres or equipment.

Setting up a simulation centre and faculty is indeed resource intensive. It includes purchase costs of equipment, physical space, faculty time and staff time to attend simulation events. Data on the costs of simulation are infrequently reported. A systematic review of studies reporting cost of simulation-based learning found only $6 \%$ reported on cost and a meagre $1.6 \%$ compared the cost with other educational interventions. ${ }^{34}$ This paucity of data makes it difficult to convince managers in control of healthcare budgets to invest in this initial outlay. They could perhaps be persuaded more readily if we look at return on investment.

Cohen $e a^{35}$ demonstrated an annual cost of simulation of $\$ 112000$ and savings of over $\$ 700000$ as a result of reduced central line blood stream infections after a simulation-based education programme. This represents a 7:1 return on investment.

With regard to paediatric outcomes, potential savings include preventing a death, significant safety event, admission to intensive care or reduced length of hospital stay. This includes offsetting legal costs or ongoing medical costs for care of a child who may have been significantly harmed. Years of functional gain to the workforce for those who survive unharmed should be considered. Less catastrophic but perhaps more frequent savings would be efficiency savings from refining processes and removing duplication or unnecessary work and better medication practices. However, if the driver for simulationbased training programmes is patient safety then perhaps the financial benefit is not the ultimate goal but the ethical gain of preventing a significant event, perhaps death, doing the right thing and 'first doing no harm'.

\section{WHAT EDUCATIONAL UNDERPINNING DO YOU NEED TO BE AWARE OF WHEN DESIGNING A SIMULATION-BASED SESSION?}

Any simulation-based learning activity should be constructed around four linked components:

> a briefing

- an immersion in the simulation-based experience

- a debrief

- an action plan to change or transform performance.

Each simulation-based learning session is best planned using a standard template (box 3) so that you can constructively build up a series of simulationbased learning activities in which there is constructive alignment between the intended learning outcomes (ILOs), the immersion, the debrief and the feedback.

The ILOs underpin which educational theory is used, whether behaviourism (cardiopulmonary resuscitation training) or constructionism (building meaning from a consultation) for example.

Simulation is often described in terms of its fidelity, usually as either high, mid or low fidelity without real understanding of what this means. This is because the term is often used interchangeably with reality. Fidelity describes how closely a simulated learning activity is to real practice. However, greater

\section{Box 3 Simulation building template}

Identify the learning need to be addressed Describe the logistics for the activity-participants needed, equipment required

- Define the learning outcomes and underpinning educational theory for your proposed teaching session Setting and background information Brief for narrator, participants and simulated patient Immersion in the simulation event-consider engagement, level of control, safety

- Expected activity/response/intervention to observethat is, what do we expect to happen?

Conclusion of session using simulation Approach to debrief and feedback 
fidelity does not necessarily lead to better learning. It is the reality of the simulation activity which influences learning. Dieckmann et $a l^{36}$ describe reality in simulation in terms of physical (smell, look and feel of the simulated environment) semantical (how the story of the simulation activity is constructed-what is accepted as believable) and phenomenological (how participants feel and think in the simulation activity).

\section{The briefing}

The ILOs are key drivers in developing any simulation-based learning activity. Advantages of ILOs are shown in box 4. Unplanned simulationbased learning activity ('let's get the manikin out and do some practice') is likely to result in unintended learning and be educationally unsafe for your learners.

\section{The immersion}

A number of other theoretical concepts need to be considered in the use of simulation to enhance learning for professional practice. Kneebone ${ }^{37}$ describes a theory of simulation as a conceptual space to build a safe learning environment. Deliberate practice theories link rehearsal to improvement and expertise. ${ }^{38} 39$ This is well exemplified by the use of rapid cycle deliberate practice training in paediatric resuscitation ${ }^{40}$ and acute paediatric scenarios in relation to repetition, practice $^{3}$ and performance. ${ }^{41}$ It is important to establish ground rules with the learner at the start of the immersion to ensure their safety.

\section{The debrief}

Most commonly, a faculty member provides time and space for the debrief. Debriefing and feedback is a two-way process, and the role of the debriefer is to enhance performance through discussion. There are many models for debriefing and feedback (box 5). ${ }^{42}$

\section{The action plan}

Part of the feedback process is developing an action plan to transfer learning from the simulated environment to the workplace. ${ }^{42}$

\section{Box 4 Advantages of intended learning outcomes}

Ensure curriculum coverage Inform learners of what they should achieve

- Inform teachers of what they should help learners to achieve

- Reflect the nature and characteristics of the profession into which the learner is being inducted

- Direct the delivery of feedback

- Align teaching with assessment and clarify what will be assessed
Box 5 Best evidence of what promotes learning using simulation

Providing constructive feedback

Allowing repetitive practice

Integrating simulation into a curricular programme

Providing a range of difficulties

Adapting to multiple learning strategies

Providing a range of clinical scenarios

- Ensuring safe, educationally supportive learning environment

- Facilitating active learning based in individual needs Issenberg et al, ${ }^{43}$ BEME report.

\section{WHAT TYPE OF SIMULATION IS BEST?}

This is dependent on your ILOs. Are they technical skills (venipuncture, lumbar puncture or examination of specific systems) or non-technical skills (communication, leadership, situation awareness or are you testing a process or system)? The relative merits and shortcomings of simulators, simulated patients and simulated environments are described in tables 2 and 3.

Evidencing up to date certification in both advanced paediatric and neonatal life support courses is now a mandatory competency to progress in paediatric training in the UK and many other countries. These courses largely result in removing clinicians from their work environment to undertake a course in a simulated environment.

It appears that knowledge improves in those attending, ${ }^{44}$ but it is unclear if this translates into improved outcomes for patients. ${ }^{45} 46 \mathrm{~A}$ recent study reports improved clinical performance tool scores with a reconstructed paediatric advanced life support (PALS) programme-where the standard teaching is divided into six simulations delivered on separate dates over a period of weeks compared with standard PALS. ${ }^{38}$ It is unclear what, if any, additional benefit is construed to patients by running simulations in the clinical environment versus the skills centre environment, but it would appear logical this is the natural progression. The key difference being that teams face a clinical scenario appropriate to their practice in their environment with their knowledge, skills, equipment and environment as it would be should that situation happen that day. Groups in Cincinnati and Sydney have highlighted the additional benefit of identifying latent failures during the simulations which, when corrected, should mitigate the failure for the next event. ${ }^{29} 47$ These centres build into the design of their simulations events from previous safety threats or identified latent failures. Despite this theoretical advantage, one of the centres has not demonstrated a superiority of in situ simulation over skills centre simulation for setting up extracorporeal membrane oxygenation for children. ${ }^{20}$ 
Table 2 Advantages and disadvantages of different types of simulators and patients supporting simulation-based learning

\begin{tabular}{|c|c|c|}
\hline & Advantages & Disadvantages \\
\hline $\begin{array}{l}\text { Simulators/manikins } \\
\text { This can include part task trainers } \\
\text { virtual reality and haptic simulators, } \\
\text { integrated simulators including } \\
\text { instructor-driven or model-driven } \\
\text { simulators }\end{array}$ & $\begin{array}{l}\text { Compliant } \\
\text { Can be set to demonstrate physical signs } \\
\text { Can be set to alter course of simulation in response to trainee } \\
\text { performance } \\
\text { Allows repeated practice in a safe environment-develops novice to } \\
\text { expert } \\
\text { Allows multiple trainees to experience the same learning experience } \\
\text { Allows instant debrief }\end{array}$ & $\begin{array}{l}\text { Limited ability for conversation } \\
\text { High fidelity versions require skilled } \\
\text { personnel to manage }\end{array}$ \\
\hline Simulated patients & $\begin{array}{l}\text { Compliant } \\
\text { Can repeat a history from real encounter } \\
\text { Can adapt to build the simulation and alter course of simulation in } \\
\text { response to trainee performance } \\
\text { Allows multiple trainees to experience the same learning experience } \\
\text { Allows instant debrief }\end{array}$ & $\begin{array}{l}\text { Students may feel less able to make } \\
\text { mistakes } \\
\text { May not have physical signs }\end{array}$ \\
\hline Real patients & $\begin{array}{l}\text { Real history } \\
\text { Real clinical signs } \\
\text { Allows instant debrief }\end{array}$ & $\begin{array}{l}\text { Poorly compliant } \\
\text { Rapidly resolving clinical signs } \\
\text { Inappropriate for large numbers of trainee } \\
\text { to examine } \\
\text { Trainees feel anxious about making } \\
\text { mistakes or looking less competent }\end{array}$ \\
\hline
\end{tabular}

\section{HOW DO I USE SIMULATION EFFECTIVELY? TIPS FOR GETTING STARTED WITH SIMULATION IN PAEDIATRICS:}

Before launching your own simulation programme, you should ask yourself a series of questions. The authors have offered some thoughts based on their own experiences

1. What do you want your learners to learn? (ILOs). Once these are agreed continue to ensure your simulation reflects this. The debriefing should be guided to ensure the ILOs are the take home message.

2. Who is your faculty-are they skilled enough to be running educationally safe experiences or do your faculty require further training. The authors would not support faculty without training in simulation building and debriefing. It is also recommended that faculty continue to have their skills reviewed with refresher training, peer review and met debriefing.
3. What equipment will you need? Less can be more. With ongoing advances in technology, it can be very tempting to reach for the newest high fidelity manikins. However, this takes skill, experience and time to work well. Critically assess if you can achieve your learning outcomes with more basic equipment and if so stick to it.

4. Are you going to use video for debriefing? Is this necessary to achieve your ILOs? Many teams introduce this into their simulations once both faculty and teams are more comfortable. For many staff, video feels threatening and the intended additional benefit to learning may be compromised.

5. Can staff be released from the clinical area, have rotas been arranged accordingly, do you need study leave?

6. Do you intend linking the simulation session to educational portfolios. Will trainees require individualised feedback, completion of Workplace Based Assessments or certificates of attendance?

Table 3 Advantages, disadvantages and similarities of simulation environments

\begin{tabular}{|c|c|c|}
\hline & Skills centres & In situ \\
\hline Advantages & $\begin{array}{l}\text { Trained faculty to design and deliver simulation } \\
\text { Trainees removed from work environment 'bleep free' time }\end{array}$ & $\begin{array}{l}\text { On site-can be fitted into clinical workload } \\
\text { Allows the system to be tested as it would be for real event-personnel, } \\
\text { equipment, environment (identifies latent failure) } \\
\text { Equitable access-involves domestics, porters } \\
\text { Cheap } \\
\text { May be more effective } \\
\text { Enhanced fidelity }\end{array}$ \\
\hline Disadvantages & $\begin{array}{l}\text { Difficulties releasing staff for offsite training (often } 1-2 \text { days) } \\
\text { Unlikely to be able to train whole team together } \\
\text { Often expensive to attend courses }\end{array}$ & $\begin{array}{l}\text { Time has to be limited as in clinical environment may be seen by patients } \\
\text { — may feel less 'safe' for both patients and staff often small core faculty }\end{array}$ \\
\hline Similarities & $\begin{array}{l}\text { Educationally robust } \\
\text { Can be linked to curriculum outcomes } \\
\text { Can be used as a workplace based assessment } \\
\text { Adaptable to any technical and non-technical skills teaching } \\
\text { Permits deliberate practice_-novice to expert }\end{array}$ & \\
\hline
\end{tabular}


7. There are some additional questions you need to give special consideration to if you anticipate in situ simulation.

8. Have the rest of the educational and clinical teams bought into this idea?

9. How are you going to ensure your clinical environment, staff and patients are prepared? How do patients feel about simulation in the bed beside them? Do your staff still feel this is a 'safe' learning environment? We have found that patients have wholeheartedly supported in situ simulation; however, we have ensured that simulations are run in cubicles or vacated bays to allow educational safety for staff.

10. Are you training only the team that work in this environment. It is unlikely that a team external to the unit will gain the same benefit and may benefit more from a simulation centre.

\section{FURTHER DEVELOPMENT}

It is anticipated that the role of simulation will continue to grow in paediatrics, particularly that of in situ simulation. The opportunities afforded by simulation in paediatrics are limitless; from simulated patients and parents for the novice to interview and examine to team training in paediatric emergencies, refining processes, that is, personal protective equipment compliance, setting up equipment or breaking bad news or communication scenarios.

The authors remain concerned that teams adopt these innovative educational opportunities without first asking themselves the questions above. There is an ongoing need for faculty development courses. Despite our reservations, there is a role for sharing prewritten simulations with the understanding that these will need adaptations for the environment for their intended use. Methods of sharing these should be explored. The authors support the development of the simulation group at Royal College of Paediatrics and Child Health and their intended creation of a bank of simulations. Fundamentally, the role of simulation in paediatrics is to support quality improvement both of training and patient safety and as such we encourage rapid dissemination and widespread sharing of good practice; we support the use of free open access medical education resources and the use of social media, we encourage peer support, review and learning from each other. We would encourage teams to publish the results of their endeavours in simulation to further shape the role it plays in the paediatric curriculum and day-to-day practice throughout the world. We would in particular support the sharing of cost-effective practices.

Contributors LC drafted the first review of the paediatric undergraduate use of simulation and the in situ simulation and contributed to the introduction. JK carried out the literature search and wrote the general review of simulation in paediatrics, the abstract and the summary. DR wrote the review of the national simulation centre work and the mobile unit.
Competing interests None declared.

Provenance and peer review Commissioned; externally peer reviewed.

Open Access This is an Open Access article distributed in accordance with the Creative Commons Attribution Non Commercial (CC BY-NC 4.0) license, which permits others to distribute, remix, adapt, build upon this work noncommercially, and license their derivative works on different terms, provided the original work is properly cited and the use is non-commercial. See: http://creativecommons.org/licenses/by$\mathrm{nc} / 4.0 /$

\section{REFERENCES}

1 Gaba D. The future vision of simulation in health care. Qual Saf Healthc 2004;12(Suppl):12-110.

2 Ahmed A, Moore H, Purva M, et al. What do senior paediatric trainees want from simulation in Yorkshire? Training Needs Assessment Survey. Arch Dis Child 2013;98:A11-13.

3 Blackwood J, Duff JP, Nettel-Aguirre A, et al. Does teaching crisis resource management skills improve resuscitation performance in paediatric residents? Paed Critic Care Med 2014;15:e168-74.

4 Reason J. Human error: models and management. BMJ 2000;320:768-70.

5 Ker J, Bradley P. Simulation in medical education. In: Swanick T, ed. Understanding medical education series, 2014:175-92.

6 Sexton JB, Thomas J, Helmreich RL. Error, stress, and teamwork in medicine and aviation: cross sectional surveys. BMJ 2000;320:745-9.

7 Royal College of Paediatrics and Child Health. Facing the Future: Standards for Paediatric Services, 2011. www.rcpch.ac. uk/facingthefuture

8 Reece A, Klaber R. Maximising learning on ward rounds. Arch Dis Child Educ Pract Ed 2012;97:61-7.

9 Hilliard R, Bannister SL, Amin H, et al. Paediatric medical education: challenges and new developments. Paediatr Child Health 2009;14:303-9.

10 Hope T, Frith P, Craze J, et al. Developing guidelines for medical students about the examination of patients under 18 years old. BMJ 2005;331:1384-6.

11 Hilliard R. Paediatr Child Health 2009;14.

12 Maran NJ, Glavin RJ. Low-to high-fidelity simulation-a continuum of medical education? Med Educ 2003;37(Suppl 1):22-8.

13 Mezirow J. Learning as transformation: critical perspectives on a theory in progress. San Francisco: Joey Bass Publishing, 2000.

14 Mileder LP, Urlesberger B, Szyld EG, et al. Simulation based neonatal and infant resuscitation teaching: a systematic review of randomised controlled trials. Kin Paediatr 2014;226:259-67.

15 Gupta AO, Ramasethu J. An innovative nonanimal simulation trainer for chest tube insertion in neonates. Paediatrics 2014;134:e798-805.

16 Rubio-Gurung S, Putet G, Touzet S, et al. In situ simulation training for neonatal resuscitation: an RCT. Paediatrics 2014;134:e790-7.

17 Mayo PH, Hackney JE, Mueck JE, et al. Achieving house staff competence in emergency airway management: results of a teaching programme using a computerised patient simulators. Crit Care Med 2004;32:2422-77.

18 Hogan MP, Pace DE, Hapgood J, et al. Use of patient simulation and the situation awareness global assessment technique in practical trauma skills assessment. J Trauma 2006;61:1047-52. 
19 Adler M, Trainor JL, Siddall VJ, et al. Development and evaluation of high fidelity simulation case scenarios for paediatric resident education. Ambul Paediatr 2007;7:182-6.

20 Falcone RA, Daughtery M, Schweer L, et al. Multidisciplinary team training using high fidelity trauma simulation. J Paediatr Surg 2008;43:1065-71.

21 Lambden S, DeMunter C, Dowson A, et al. The Imperial Paediatric Emergency Training Toolkit (IPETT) for use in paediatric emergency training: development and evaluation of feasibility and validity. Resuscitation 2013;84:831-6.

22 Burmester M, Lane M, Ghez O. Simulated Paediatric Resuscitation Team Training SPRinT. http://www.rbht.nhs.uk/ healthprofessionals/education/sprint/team (accessed 23 Aug 2014).

23 Eppich W, Adler MD, McGaghie WC. Emergency and critical care paediatrics: use of medical simulation for training in acute paediatric emergencies. Curr Opin Paediatr 2006;18:266-71.

24 Theilen U, Leonard P, Jones P, et al. Regular in situ simulation training of paediatric medical emergency team improves hospital response to deteriorating patients. Resuscitation 2013;84:218-22.

25 Draycott TJ, Crofts JF, Ash JP, et al. Improving neonatal outcome through practical shoulder dystocia training. Obstet Gynecol 2008;112:14-20.

26 Barsuk J, Cohen E, McGaghie W, et al. Long-term retention of central venous catheter insertion skills after simulation-based mastery learning. Acad Med 2010;85(Suppl 10):S9-12.

27 Chaer RA, Derubertis BG, Lin SC, et al. Simulation improves resident performance in catheter-based intervention: results of a randomized, controlled study. Ann Surg 2006;244:343-52.

28 Andreatta P, Saxton E, Thompson M, et al. Simulation-based mock codes significantly correlate with improved pediatric patient cardiopulmonary arrest survival rates. Pediatr Crit Care Med 2011;12:33-8.

29 Patterson MD, Geis GL, Falcone RA, et al. In situ simulation: detection of safety threats and teamwork training in a high risk emergency department. BMJ Qual Saf 2013;22:468-77.

30 Greenaway D. Shape of Training in UK Report, 2013. http:// www.shapeoftraining.co.uk (accessed 20 Aug 2014).

31 Sharek PJ, Classen D. The incidence of adverse events and medical error in paediatrics. Pediatr Clin North Am 2006;53:1067-77.

32 Pearson G. Why children die: the report of a pilot confidential enquiry into child death by $\mathrm{CEMACH}$ (Confidential Enquiry into Maternal and Child Health). Clin Risk 2008;14:166-8.
33 Spedding R, Jenner R, Potier K. Blended learning in paediatric emergency medicine: preliminary analysis of a virtual learning environment. Eur J Emerg Med 2013;20:98-102.

34 Zendejas B, Wang AT, Brydges R, et al. Cost: the missing outcome in simulation-based medical education research: a systematic review. Surgery 2013;153:160-76.

35 Cohen ER, Feinglass J, Barsuk JH, et al. Cost savings from reduced catheter-related bloodstream infection after simulation-based education for residents in a medical intensive care unit. Simul Healthc 2010;5:98-102.

36 Dieckmann P, Gaba D, Rall M. Deepening the theoretical foundations of patient simulation as social practice. Simul Healthc 2007;2:183-93.

37 Kneebone RL. Crossing the line: simulation and boundary areas. Simul Healthc 2006;1:160-3.

38 Ericsson K. Deliberate practice and the acquisition and maintenance of expert performance in medicine and related domains. Acad Med 2004;79(Suppl 10):S70-81.

39 McGaghie WC, Issenberg SB, Cohen ER, et al. Medical education featuring mastery learning with deliberate practice can lead to better health for individuals and populations. Acad Med 2011;86:e8-9.

40 Hunt EA, Duval-Arnould JM, Nelson-McMillan KL, et al. Paediatric resident resuscitation skills improve after rapid cycle deliberate practice. Resuscitation 2014;85:945-512014.

41 Schmutz J, Eppich W, Hoffmann F. Five steps to develop checklists for evaluating clinical performance: an integrative approach. Acad Med 2014;89:996-1005.

42 Fanning RM, Gaba D. The role of debriefing in simulation based learning. Simul Healthc 2007;2:115-25.

43 Issenberg SB, McGaghie W, Petrusa ER, et al. Features and use of high fidelity medical simulations that lead to effective learning: a BEME systematic review. Med Teach 2005;27:10-28.

44 Carapiet D, Fraser J, Wade A, et al. Changes in paediatric resuscitation knowledge among doctors. Arch Dis Child 2001;84:412-14.

45 Jabbour M, Osmond MH, Klassen TP. Life support courses: are they effective? Ann Emerg Med 1996;28:690-8.

46 Kurosawa H, Ikeyama T, Achuff P, et al. A randomized, controlled trial of in situ paediatric advanced life support recertification ('paediatric advanced life support reconstructed') compared with standard paediatric advanced life support recertification for ICU frontline providers. Crit Care Med 2014;42:610-18.

47 O'Leary F, McGarvey K, Christoff A, et al. Identifying incidents of suboptimal care during paediatric emergencies-an observational study utilising in situ and simulation centre scenarios. Resuscitation 2014;85:431-6. 